\title{
Isolated Shoulder Palsy due to a Cortical Infarction
}

\author{
Hiromasa Tsuda, Yawara Kubota, Kozue Tanaka and Shuji Kishida
}

Key words: homunculus, magnetic resonance imaging (MRI), ozagrel sodium, precentral gyrus, primary motor cortex, pure motor monoparesis

(Intern Med 50: 947, 2011)

(DOI: 10.2169/internalmedicine.50.4928)
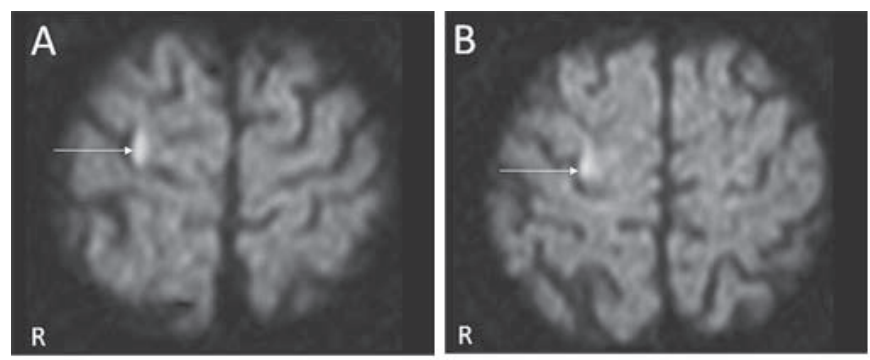

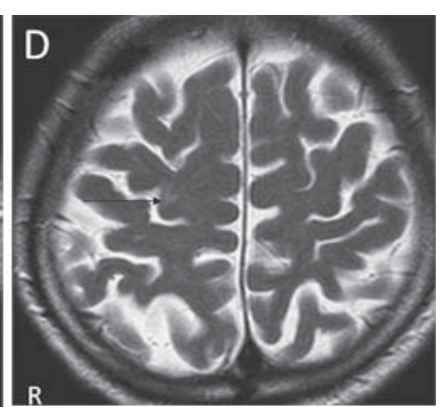

Picture 1.
A 75-year-old man with hyperlipidemia suddenly presented with difficulty in lifting his left arm, despite the lack of shoulder pain. Moderate weakness restricted to the left shoulder with normal joint flexibility was observed, despite normal muscle strength in the elbow, wrist and fingers. There were no other neurologic abnormalities. Shoulder magnetic resonance imaging (MRI) findings were normal. Cranial MRI (Picture 1A, B: diffusion-weighted image, Picture 1C, D: T2-weighted image) demonstrated a small infarction in the right precentral gyrus (arrow). Electrocardiogram, echocardiogram, and carotid ultrasonography demonstrated normal findings. Because atherothrombosis was considered, intravenous ozagrel sodium was initiated. Thereafter, he became asymptomatic within 10 days.

In the primary motor cortex, there is a broad somatotopic representation of the different body parts in an arranged order, and the area corresponding to the shoulder is very small. Therefore, to date there are only 2 reported cases of isolated shoulder palsy due to a cortical infarction detected by diffusion-weighted MRI $(1,2)$.

The authors state that they have no Conflict of Interest (COI).

\section{References}

1. Nah HU, Park HK, Kang DW. Isolated shoulder weakness due to a small cortical infarction. J Clin Neurol 2: 209-211, 2006.

2. Komatsu K, Fukutake T, Hattori T. Isolated shoulder paresis caused by a small cortical infarction. Neurology 61: 1457, 2003.

Department of Neurology, Tokyo Metropolitan Cancer and Infectious Diseases Center Komagome Hospital, Japan Received for publication December 2, 2010; Accepted for publication January 24, 2011

Correspondence to Dr. Hiromasa Tsuda, hiromasatsuda@ cick.jp

(C) 2011 The Japanese Society of Internal Medicine Journal Website: http://www.naika.or.jp/imindex.html 